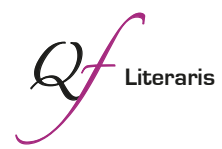

\title{
Imagen de la mujer en Sueño en el Pabellón Rojo. La construcción y la transgresión del género
}

\author{
The image of woman in Dream of the Red Chamber. \\ The construction and transgression of gender
}

\author{
Teresa I. Tejeda Martín
}

teresa.i.tejeda@gmail.com

Recibido: 13/04/2018. Aceptado: 13/08/2018

Resumen: En este artículo proponemos una reflexión sobre cómo se construye la imagen de la mujer de élite en Sueño en el Pabellón Rojo a través del grupo de las "doce bellezas", para poder analizar después a Baoyu y Xifeng, los dos protagonistas que cuestionan y transgreden los límites de la categoría de género. Se tendrán en cuenta tanto teorías feministas que abordan el concepto de género, como el pensamiento que ha conformado la naturaleza femenina dentro de la tradición china.

Palabras clave: Sueño en el Pabellón Rojo; imagen de la mujer; género; yin y yang; confucianismo.

\begin{abstract}
In this paper we propose a reflection about how the elite women image is build in Dream of the Red Chamber through the twelve beauties's group, in order to analyze Baoyu and Xifeng, the two protagonists who question and transgress the boundaries of the category of gender. It will be taking on account both, feminist theories, which deal with the gender concept, and the though system that shaped the female nature within the Chinese tradition.
\end{abstract}

Keywords: Dream of the Red Chamber; women images; gender; yin and yang; Confucianism. 



\section{De la crítica feminista al yin y el yang}

Sueño en el Pabellón Rojo ${ }^{1}$, escrita en la primera mitad del siglo XVIII, se considera una de las grandes obras clásicas de la narrativa de ficción en la tradición literaria china a la vez que uno de los mejores retratos de la vida de la mujer en la China Imperial. Desde su aparición, suscitó un gran interés entre los académicos por lo que la cantidad de comentarios críticos que han versado sobre la obra, entre diferentes escuelas de interpretación a lo largo de su historia, resulta abrumadora, hasta el punto de que en tiempos más recientes estas interpretaciones se han convertido en objeto de análisis en sí mismas (Yu, 1997: 12). Uno de los comentarios que acompañó a la novela desde que circulara en manuscritos y que llegó a alcanzar tanta importancia como el texto en sí, fue el de Zhinyan Zhai, quien perteneció a su audiencia original y cuyo principal foco se ponía en la reconstrucción de las relaciones familiares del escritor principal Cao Xueqin ${ }^{2}$, tendencia que después han seguido ciertos críticos (Ge, 2002: 57). Pero aunque sea posible establecer ciertas relaciones entre su experiencia vital y la decadencia de la familia ficticia Jia, en torno a la que gira la trama de esta novela, limitarnos a eso sería empobrecer las posibilidades de un texto que nos abre la ventana a numerosos aspectos de la sociedad y de las convenciones literarias de la dinastía Qing.

La lectura que proponemos en este artículo se basa precisamente en los vínculos que esta novela establece tanto con las tradiciones sociales como literarias a la hora de construir y transgredir la imagen de la mujer. A pesar de que la obra ofrece una gran variedad de personajes femeninos, limitaremos nuestra reflexión a las mujeres consideradas de élite relegadas a los cuartos interiores cuando abordemos la construcción de la imagen de la mujer, concretamente a las consideradas

\footnotetext{
${ }^{1}$ La versión definitiva de la novela de 120 capítulos fue publicada en 1791-1792. Los primeros 80 se atribuyen a Cao Xueqin (1715-1764) y los últimos 40 capítulos, al editor Gao E (1738-1815). Aunque la autoría del libro ha sido ampliamente discutida, esta es la hipótesis más extendida.

${ }^{2}$ Perteneciente a una familia de funcionarios de gran prestigio y poder venida a menos por las luchas internas en la sucesión del trono entre el emperador Kangxi y Yongzheng. El autor se vio obligado a trasladarse de Nanjing a Pekín, donde acabó sumido en la pobreza.
} 
“doce bellezas”十二美人 shi'er meiren ${ }^{3}$, que responden al estereotipo femenino proyectado en la literatura del siglo XVIII y que conforman un ideal que engloba desde lo físico hasta aspectos como la educación, el comportamiento, los valores y las aficiones ${ }^{4}$. Para después poder comprender la transgresión de la categoría normativa del género femenino de los dos personajes de la novela, Xifeng y Baoyu, que son el objetivo final de este estudio. La ruptura de los límites del género establecidos por la tradición cuestionará a la vez que reforzará dicha categoría.

A este respecto, encontramos varias interpretaciones feministas de la novela que posicionan al principal autor frente a su propia tradición, y que intentan demostrar que ese retrato tan exhaustivo de la mujer es una denuncia contra las duras condiciones que sufría bajo la moral neoconfuciana de la Dinastía Qing. Así lo hace Zhao Rong, a la que también se suman otros críticos como Moss Roberts y Keith MacMahon $^{5}$. Sin embargo, en estas páginas nos situamos en la línea de Louise Edwards cuando critica estos puntos de vista que, en su opinión, perpetúan el sistema patriarcal que pretenden denunciar, para centrarnos en cómo se retrata la mujer al margen de la posible reivindicación de su subyugación que el texto pudiera llegar a contener (1990b: 408).

Para realizar esta tarea adoptaremos un punto de vista comparativo al contemplar como herramienta de análisis las intersecciones entre la teoría feminista, que surge de la distinción entre sexo y género pro-

\footnotetext{
${ }^{3}$ Un concepto de larga tradición histórica y social ya presente en la Dinastía Tang, y que se perpetuó a través de la literatura y, en ciertas épocas, de la pintura hasta la dinastía Qing. Dependiendo de la época se ha referido también a concubinas y cortesanas (Wu, 1997: 323).

${ }^{4}$ Uno de los títulos alternativos de Sueño en el Pabellón Rojo era Las doce bellezas de Jinling, como el mismo Cao Xueqin explica en el primer capítulo del libro.

${ }^{5}$ Así se refleja en Zhao Rong (1982) hunyin ziyou de nahan nannüpingdeng de ouge (Un grito por la libertad en el matrimonio y un elogio a la igualdad de sexos). 《贵阳师院学报》guiyan shiyuan xuebao, vol. 1: 55-65; Moss Roberts (1978) "Neoconfucianism in the Dream of the Red Chamber: a critical note", Bulletin of Concerned Asian Scholar, vol. 10(1): 63-66; Keith MacMahon (1988) "A Case for Confucian Sexuality: the Eighteenth Century Novel 'Yesou puyan'” Late Imperial China, vol. 9(2): 32-55.

${ }^{6}$ Dice Edwards: "La simple inversión de género no necesariamente implica que la novela expresa un sentimiento antipatricarcal. Más bien, la mera inversión del falogocentrismo, el hombre/mujer, el binario yin/yang podría reforzar aún más la fundación patricarcal porque 'invertir el orden sólo repite el mismo sistema' (Furman, 1986: 7475)" (1990b: 410).
} 
puesta por Beauvoir y que abarca enfoques como el de Hélène Cixous, y el principio sobre el que se ha construido el concepto de género en el pensamiento chino: el yin y el yang. Sin querer equiparar tradiciones, mostraremos lo que tienen de complementarios estos enfoques a la hora de cuestionar desde la crítica literaria los estereotipos femeninos en la ficción.

\subsection{El género como constructo social}

Simone de Beauvoir, una de las teóricas feministas más reconocidas, inicia uno de los capítulos de su obra de referencia El segundo sexo escrito en 1949 con la famosa frase "No se nace mujer, se llega a serlo" (1970: 87). La pensadora francesa, que nos da una de las bases sobre la que cimentamos nuestra lectura, defiende que la naturaleza femenina no existe, y por tanto, la mujer no está determinada por su nacimiento, sino por una serie de presupuestos socio-culturales que determinan su identidad, y que están asociados a la diferencia biológica entre el macho y la hembra. Debemos hacer una clara distinción entre lo que es el sexo, una categoría biológica, y el género, un hecho social. Cuando analizamos una cultura masculina y jerarquizada, como es la que nos compete, la mujer es el individuo subordinado y, en palabras de Elena Gajeri: "relegada a la perenne alteridad respecto al sujeto masculino" (2002: 452). De modo que el papel de la mujer, así como su representación literaria, estaría determinado por las expectativas, las convenciones y la educación que se imponían sobre ella.

Con su teoría, Beauvoir dio cabida a una mayor gama de géneros posibles no necesariamente identificados con las dos categorías biológicas de macho y hembra, y que postulaban la mutabilidad y la fluidez de los individuos. En este sistema organizado a partir del hombre, la mujer sería el polo negativo de todas las posibles parejas opositivas: sujeto/objeto, cultura/naturaleza, actividad/pasividad, etc., lo que en $L a$ risa de la medusa de Hélène Cixous se definiría como el "pensamiento binario machista" (1995: 14). La teórica está influenciada por el pensamiento de Jacques Derrida, que defiende que tanto la filosofía como el pensamiento literario occidental se han visto siempre atrapados en una serie de oposiciones binarias que "en último término, siempre vuelven a la pareja fundamental de masculino/femenino" (Moi, 2006: 114). Un 
par que, en nuestra opinión, no es exclusivo de la cultura que dio lugar a esta hipótesis, sino que la trasciende, aunque sea con matices.

\subsection{Yin $y \operatorname{yang}^{7}$ y la dinámica del género}

El pensamiento chino sigue un modelo generativo, que se opone al modelo causal que busca la existencia de un Dios o elementos constitutivos del universo que doten de sentido al mundo. Se entiende la realidad como un continuum movido por un ritmo cíclico o movimiento permanente que provoca la mutación de la vida. La figura del yin y el yang, dos fuerzas que en su evolución de la una a la otra describen un círculo, representa la globalidad del mundo en continuo movimiento provocado por el qi, la energía vital que anima al universo. Este modelo cíclico privilegia un sistema de pensamiento binario o de oposiciones complementarias. Estos pares opuestos que han conformado la visión china tradicional del mundo y la sociedad, según Anne Cheng, no responden a una estructura "dualista en el sentido disyuntivo mencionado anteriormente, sino ternario por cuanto integra la circulación del soplo que une ambos términos" (2003: 37). Su movimiento giratorio implica un centro que, aunque nunca es fijo, es real y constante.

Este principio de complementareidad después se ha aplicado a otros fenómenos del mundo como sonido/silencio, mente/cuerpo, y a lo que más nos interesa en este estudio, hombre/mujer. El yin asociado a lo femenino, inferior, pasional y la oscuridad, y el yang a los valores positivos contrarios constituyen, por tanto, el principio sobre el que se ha construido el género en el pensamiento chino. El taoísmo y el confucianismo partirán posteriormente de estos pares complementarios para explicar la diferencia entre los géneros. ${ }^{8}$ Karyn Lai, por su parte, ha rechazado la idea de la polaridad al señalar que lo femenino y lo mas-

\footnotetext{
${ }^{7}$ Aunque los orígenes del yin y el yang permanecen oscuros, se cree que los conceptos surgieron a partir de una polaridad básica: el paso de la luz a la oscuridad, y su correspondiente paso del paso del frío al calor. La grafía de los caracteres se relaciona con este origen; el carácter tradicional chino de yin 陰 representa la parte norte, nubosa y sombría de una montaña, mientras que el de yang 陽 representa el lado sur, soleado y luminoso.

${ }^{8}$ Tradicionalmente se ha asociado lo femenino con lo menos privilegiado, pero encontramos interpretaciones más recientes que han intentado invertir el orden de este pensamiento, como la de Karyn Lai (2000) en "The Daodejing: resources for contemporary feminist thinking" que toma el Daodejing, como la fuente del pensamiento feminista
} 
culino no son conceptos excluyentes sino interdependientes, por lo que la presencia de uno no excluye la ausencia del otro, así como que sean conceptos estáticos, pues están sujetos a constantes cambios (2000: 131-153). En este sentido, también resalta Andrew Plaks que cuando hablamos de dualismo en el pensamiento chino no hay que caer en el error de creer que nos enfrentamos a dos polos "estables" sino más bien a una categorización que atiende a la presencia o al grado de intensidad de alguna cualidad (1976: 43), es decir, a cómo una diferencia cuantitativa llega a ser una diferencia cualitativa.

\subsection{Yin y yang y las oposiciones binarias feministas}

La construcción del género a través de oposiciones binarias nos lleva de nuevo a la teoría feminista de Hélène Cixous y su concepto "pensamiento binario machista", pues enumera las siguientes oposiciones binarias, que se corresponden con las oposiciones del yang y el yin: "Actividad/Pasividad, Sol/Luna, Cultura/Naturaleza, Día/Noche, Padre/Madre, Cabeza/Corazón, Inteligible/Sensible, Logos/Pathos" (Moi, 2006: 114). Para la teórica, los términos femenino y masculino no podrían existir el uno sin el otro, al igual que no podría existir el yin sin el yang. Precisamente este es el punto de intersección entre las dos teorías que nos permite tenerlas en cuenta en su conjunto para entender e interpretar la construcción y la transgresión de la imagen de la mujer en Sueño en el Pabellón Rojo, siempre teniendo en cuenta que en el pensamiento chino no hay una posición de alteridad tan tajante.

Además, cabe destacar que la estructura binaria está presente en toda la novela, no solo respecto a la construcción del género sino también en el juego entre la realidad y la ilusión e, incluso, en la construcción de personajes complementarios, como se aprecia en dos de los personajes femeninos protagonistas, Daiyu y Baochai. Michael Yang subraya que esta dicotomía entre lo verdadero y lo falso y entre el ser y la nada, determina la estructura total de Sueño en el Pabellón Rojo, básicamente basada en el concepto tradicional de yin y yang (1996: 74). A lo largo de la narración hay un constante juego de dobles sentidos, que atañe también a la elección de los nombres de los personajes.

contemporáneo, invirtiendo los valores asociados a lo femenino y a lo masculino, priorizando las características asociadas a la mujer. 
Una vez expuestas las principales líneas que usaremos en el análisis de la imagen de la mujer en Sueño en el Pabellón Rojo, pasemos a reflexionar sobre los pilares en los que se ha apoyado su construcción.

\section{La conformación de la imagen de la mujer en el pensamiento tradicional}

Tendremos en cuenta en este punto cuáles son aquellos aspectos que han determinado la imagen de la mujer y que han condicionado la percepción que se tenía de ella. Para lo cual tomaremos tres aspectos fundamentales sobre los que se han construido los personajes considerados como las "doce bellezas".

\subsection{Posición de la mujer en el orden confuciano}

Confucio ha ofrecido un código ético de comportamiento basado en la piedad filial, la humanidad o benevolencia, y los ritos o las reglas de corrección, que ha guiado durante cientos de años al hombre chino en su manera de vivir correctamente. El considerado gran sabio concebía al hombre a través de los vínculos que establecía con los demás y que determinaban su posición en un orden jerárquico establecido, basado en criterios de edad y género. De entre las ideas más importantes que defiende en su doctrina tiene especial importancia aquí el concepto de piedad filial 孝 xiao, que consiste en el deber de obedecer y respetar a los mayores y no contravenir sus deseos hasta el punto de ponerlos por encima de la propia voluntad ${ }^{9}$. Todo lo que hiciera un miembro de la familia afectaba al resto, de lo que se deriva que una mujer, como miembro de ese entramado social y en una posición inferior, no podía expresar ningún interés que pudiera ir en su contra. Aunque hay que destacar que Confucio no habló apenas de la mujer, excepto en una de sus $\operatorname{citas}^{10}$, y que fueron principalmente sus discípulos, como argumenta Sandra Wawrytko, los que posteriormente desarrollaron un

\footnotetext{
${ }^{9}$ Este concepto ha sido apoyado y amplificado por un gran corpus de textos elevados a la categoría de clásicos a lo largo de la tradición, tales como el Libro de los Ritos 礼记 liji o el Clásico de la Piedad Filial 孝经 xiaojing, entre otros.

10 "Las gentes más difíciles de crear son las doncellas y los villanos. Tratados con familiaridad, se vuelven insolentes. Tratados con distancia, se llenan de resentimiento". (Confucio XVII.25, 1997: 124)
} 
pensamiento misógino que llegó a su apogeo a partir del siglo XVI al implantarse el neoconfucianismo (2001: 174).

Es entonces cuando se establecen las reglas que limitan la vida de la mujer y que se verán reflejadas en el código ético de la novela, estas son las conocidas como las "Tres Obediencias"三从sancong: obediencia al padre como hija, a su marido como esposa y a su hijo como viuda. Acompañadas por las “Cuatro Virtudes” 四德side: fidelidad o castidad, encanto físico, propiedad al hablar y eficacia en las labores ${ }^{11}$. Resalta Lisa Raphals que de este modo era imposible su independencia, y que estaban obligadas a mantener una relación de sumisión con respecto al hombre (1998: 217). Esta moral cada vez más estricta queda reflejada especialmente en el comportamiento de algunos de los personajes femeninos integrados en una familia con una fuerte tradición confuciana y patriarcal. Mencionemos como ejemplo a Baochai, la mayor representante de rectitud moral y el personaje más sumiso y obediente de la novela. La muchacha, ante la propuesta que le hace su madre de contraer matrimonio con Baoyu, responde:

No debería hacerme esa pregunta a mí, madre. El matrimonio de una muchacha lo deciden sus padres. Como mi padre ha muerto, la decisión es suya o, en todo caso, puede consultarla con su hijo mayor, pero no debe preguntarme a mí (Cao y Gao, 2005: 316).

Baochai resulta constantemente ensalzada como un dechado de virtudes pues parece ajustarse a la más estricta moral de la época de la novela. Otro personaje que cabe destacar en este sentido es Li Wan, que representa los valores ideales asociados a la viudedad. Ann Waltner señala que "la moralidad confuciana consideraba indecoroso para una viuda volver a casarse, a pesar de poder verse obligada por causas de fuerza mayor" (1981: 129) y así se hace eco en la literatura ${ }^{12}$. La castidad era exigida a la mujer tanto de soltera como de viuda. Por lo que Li Wan al quedarse viuda regresa a un estado de castidad propio de una

\footnotetext{
${ }^{11}$ La fidelidad y la castidad han sido los valores más apreciados tradicionalmente de una mujer pero nunca fueron tan rígidos como en la Dinastía Qing.

${ }^{12}$ Por ejemplo, La injusticia contra Dou E que conmovió el cielo y la tierra, de Guan Hanqing, cuenta la historia de Dou E, una joven viuda que se ve forzada a volver a casarse pero antes de aceptar el chantaje prefiere la muerte. Igual que una soltera, una viuda debía permanecer casta, o mancharía el honor de toda la familia.
} 
dama célibe, pues acaba trasladándose a vivir con las otras damas solteras al Jardín de la Vista Sublime, una burbuja separada del mundo de las casadas y por tanto del mundo sexualmente activo.

\subsection{El espacio de la mujer: lo público y lo privado}

En la sociedad china antigua se crearon dos ámbitos que separaron la vida de los hombres y de las mujeres, a las que les corresponde el ámbito privado, separado del mundo exterior, reservado para ellos. Y así se refleja ya en el Libro de los ritos 礼记Liji, compilado en los últimos siglos de la dinastía Zhou, en el que la separación de los sexos estaba estrictamente marcada casi desde el nacimiento. Susan Mann apunta que dicha segregación entre el hombre y la mujer se producía cuando la niña perdía sus dientes de leche (1997: 55). En el mencionado clásico ya se especificaba que los hombres y las mujeres solteras no deberían tener contacto, incluso ni saber los nombres los unos de los otros, conteniendo numerosas prohibiciones en este sentido ${ }^{13}$.

El pensamiento confuciano siguió relegando a la mujer a la esfera privada y al hombre a la esfera pública, aunque vemos que esta norma no se cumple estrictamente en Sueño en el Pabellón Rojo, pues Baoyu representa una excepción que resulta crucial a la hora de reflexionar sobre la transgresión del género. Para el resto de los personajes masculinos se observa una escrupulosa separación entre las mujeres y los hombres. La entrada de cualquier hombre está prácticamente vetada en el jardín donde habitan las doncellas, incluso cuando las doncellas requerían atención del médico se hace con el mayor de los cuidados usando una cortinilla que la protegiera de la vista masculina.

La vida de la mujer transcurría en los cuartos interiores ocupada normalmente con sus labores, aunque a veces buscaban otras actividades para entretenerse. En la novela las jóvenes ocupantes del jardín fundan una academia de poesía, pero siempre teniendo muy en cuenta que nunca pasaría de un mero divertimento. A pesar del aumento de

\footnotetext{
${ }^{13}$ Véase por ejemplo pasajes como "Los asuntos externos no se deben hablar dentro del umbral del apartamento de las mujeres, ni los asuntos del interior de las mujeres fuera de él. [...] Ni siquiera el padre y la hija debían ocupar la misma esterilla. El hombre y la mujer, sin la intervención de un casamentero, no deben conocer sus nombres. A menos que se hayan recibido los regalos de la unión, no debe haber comunicación ni afecto entre ellos" (Lijing. Tratado de los Ritos, 2005, vol. 1: 89-90).
} 
mujeres escritoras o alfabetizadas en las familias de élite en la realidad, rasgo que hasta el momento era más propio de las cortesanas, nunca se permitió la poesía como primera ocupación o profesión, que debía ser la de esposa ${ }^{14}$. En relación con el club de poesía Baochai, siempre dentro de la corrección moral, dice:

No estaría bien visto si la cosa llega a saberse. Como dice el viejo proverbio: "En la mujer la falta de talento es virtud"15. Para nosotras la conveniencia más importante es ser castas y tranquilas. [...] A muchachas de familias como las nuestras no nos conviene tener fama de inteligentes (Cao y Gao, 1988b: 577).

Además, el aislamiento de una mujer se agravaba por los pies vendados, que reducían y dificultaban notablemente su movilidad. Las salidas al exterior eran algo excepcional que se producían en momentos muy concretos, como un funeral, la visita a un templo o para las mujeres casadas una visita a su propia familia, y que implicaban tanto la compañía de sirvientes y doncellas, como el permanecer ocultas en sus palanquines.

\subsection{La educación y el aprendizaje de las reglas}

El principal objetivo en la educación de las muchachas era inculcarles las reglas y maneras de ser una esposa, el conocido como fudao 妇道. Además, tenían que educarse en otras tareas, como rituales de adoración a los ancestros, manejo de la casa, música, pintura y, dependiendo del grado de apertura de los padres, aprender a leer y a escribir. En Sueño en el Pabellón Rojo nos encontramos con personajes con una buena instrucción, incluso iniciadas en los clásicos confucianos lo que, a pesar de las restricciones que se le imponían a una mujer, no estaba específicamente sancionado por las reglas de conducta ${ }^{16}$. Históricamente, en las

\footnotetext{
${ }^{14}$ En el siglo XVII en la provincia de Jiangnan había muchas familias de elite importantes que permitían que sus mujeres escribieran incluso se les llegó a imprimir algunos trabajos, pero la moral neoconfuciana era estricta en este sentido: "la voz de una mujer debería estar contenida en los cuartos de la mujer" (Epstein, 2007: 98).

${ }^{15}$ Frase de Chen Jiru (1558-1639) que ha pervivido hasta nuestros días como un prejuicio confuciano.

${ }^{16}$ En el Libro de los ritos se habla de la edad apropiada para aprender cada cosa, pero no es explícita la restricción de la educación al género.
} 
familias de élite en la dinastía Qing, cada vez resultaba más común que las mujeres recibieran cierta formación, pues se consideraba un aspecto de valor creciente a la hora de concertar un matrimonio. Según Susan Mann "la educación de una hija encarnaba la trayectoria de erudición de su familia natal y eso la hacía más casadera" (1997: 59) ${ }^{17}$.

La educación de Daiyu, por ejemplo, resultaba algo excepcional, comparada con la de Li Wan o Xifeng, incluso para ser una niña de buena familia. ${ }^{18}$ Esto provoca que otros personajes, más ajustados al ideal que venimos definiendo, la censuren. Por muy elevados que sean los conocimientos de una mujer, su comportamiento nunca debía traspasar los límites establecidos por las reglas, las que la obligaban a comportarse por encima de todo con humildad. En boca de Baochai encontramos las siguientes palabras dirigidas a Daiyu, quien sentía un ansia de aprender más:

[...] deberíamos limitarnos a las labores domésticas. Y si en algún caso contamos con una educación elemental, deberíamos elegir libros apropiados. Si nos dejamos influenciar por esos libros heterodoxos pronto veremos nuestra naturaleza y nuestros sentimientos irremediablemente corrompidos (Cao y Gao, 1988b: 38).

Daiyu, será un personaje que pague con su vida y su reputación, el no ajustarse a los parámetros que constantemente le recuerda Baochai con su comportamiento y sus palabras. Los libros considerados apropiados eran muy limitados, y así lo estaba la propia educación de las mujeres y su acceso la cultura ${ }^{19}$.

Los tres aspectos tratados hasta ahora determinan la construcción de la imagen de la mujer y responden al sistema de pensamiento imperante durante los años de composición de la novela, así como a las

\footnotetext{
${ }^{17}$ Para la fluidez de la lectura de este artículo se han traducido al español las citas de las obras consultadas escritas en inglés.

${ }^{18}$ Hay que tener en cuenta que de algún modo se justifica este hecho como la manera de sus padres de compensar la falta de un hijo varón (Cao y Gao, 1988a: 64)

${ }^{19}$ Existían varios libros que se tomaron como referencia para su educación y que son mencionados también en la narración, como Lienü zhuan un texto de la dinastía Han que se revisó durante la dinastía Ming; Nü Jie escrito por Ban Zhao en el siglo II a.C. y que habla sobre el comportamiento de las mujeres; Nüxiaojing, un clásico sobre la piedad de la mujer escrito en la dinastía Tang; y unos comentarios escritos por Yuan Cai en sus Preceptos Familiares (dinastía Song) (Hirsch, 1991: 6).
} 
reglas sociales y la tradición literaria. Ya el comentarista Zhiyan Zhai analizó a las "doce bellezas" como un grupo de personajes individuales a la vez que como un arquetipo colectivo de numerosas chicas (en $\mathrm{Wu}$, 1997: 309), es decir, la generalización a través de la individualización. Otros aspectos como la belleza de la mujer, que abarcaba tanto lo físico como la decoración de sus aposentos o sus actividades, también se codificaron a finales de la dinastía Ming y Qing, pero por cuestiones de espacio no nos detendremos en ello. En el siguiente capítulo pasaremos a analizar a los dos personajes objeto de nuestro estudio, Baoyu y Xifeng, cuya descripción y comportamiento cuestionarán las categorías del género descritas en los epígrafes anteriores.

\section{La transgresión de los límites del género: Baoyu y Xifeng}

Dentro de la novela nos encontramos con Baoyu y Xifeng, que traspasan los límites establecidos convencionalmente, lo que los convierte, en nuestra opinión, en los dos personajes más complejos de la misma. Baoyu, biológicamente un hombre, adquiere muchos de los comportamientos adscritos al género femenino, del mismo modo que Xifeng, una mujer, se comporta a menudo siguiendo los parámetros del género masculino.

\subsection{Baоyu y su naturaleza ambigua}

Hoy en día, un análisis de este personaje se ajustaría más a lo que Judith Butler ha llamado Queer Studies, ya que se resiste a las categorías de hombre o mujer, haciendo gala de una construcción con matices mucho más flexibles. Louise Edwards subraya que al hablar de la ideología sexual en este caso nos referimos al género y no al sexo, es decir: "a los constructos sociales, conscientes e inconscientes, que asocian a un individuo con el modo masculino o femenino" (1990a: 70).

En el caso de Baoyu veremos cómo se hace una inversión de valores de las oposiciones binarias que hemos mencionado en anteriores apartados posicionando lo femenino como positivo, aunque el desenlace de este personaje sea un tanto polémico a la hora de sacar conclusiones sobre el significado de dicha subversión.

Cixous y Kristeva han planteado la posibilidad de que exista en cada individuo un balance entre los principios asociados al hombre y los 
principios asociados a la mujer, por lo que existe a su vez la posibilidad de romper ese balance inclinándose más hacia uno de los polos. Cixous habla de una "bisexualidad metafórica" para referirse a la simultaneidad de lo femenino y lo masculino en un ser sin atender a jerarquías que atiendan a la convención social (1995: 44). Y estas teorías, se ponen en relación con el concepto de yin y yang, dos fuerzas en constante movimiento e interacción entre ellas que pueden pasar de la una a la otra. Al igual que las feministas consideran que la balanza se puede inclinar hacia uno de los polos, estas dos fuerzas podrían llegar a invertirse. Louise Edwards dice que "el retrato del principal protagonista de la novela Jia Baoyu revela la interacción entre el yin y el yang muy claramente" (1990a: 72). Por lo que si la construcción del género puede ser explicada por la mayor presencia de una de las fuerzas o de otra, la transgresión del mismo puede achacarse a las mismas razones. En este caso consideramos que en el personaje de Baoyu no solo se da una fuerte interacción de las dos fuerzas, lo que le hace tan controvertido, sino que en muchos casos se impone el yin sobre el yang, como ejemplificaremos a continuación.

La naturaleza de Baoyu resulta ambigua desde el primer momento en que aparece en la novela tanto para el lector como para los personajes de la misma. La primera vez que se hace mención a este asunto es en boca de Leng Ziying, un anticuario que conoce la historia familiar de los Jia y quien los presenta en el segundo capítulo. Cuenta cómo Baoyu, al enfrentarse al ritual que se hacía por costumbre durante el primer cumpleaños de un niño para comprobar cuáles eran sus impulsos naturales, se había decantado por objetos femeninos, frente a otros como tinta, papel o un pincel:

Aunque te parezca mentira, ¡los ignoró todos salvo el colorete, las polveras, los adornos para el pelo y unos pendientes! Su padre montó en cólera y predijo que el chico llegaría a ser un libertino disoluto. Por eso no lo quiere mucho, a pesar de que el niño sigue siendo el favorito de la abuela (Cao y Gao, 1988a: 69).

Baoyu revela desde este momento una naturaleza especial, mostrando ya una inclinación por el mundo femenino. A la vez, apreciamos la presión que ejercían las familias sobre sus hijos para que hicieran la carrera de funcionarios. Señala Susan Mann que a los ocho años aproxi- 
madamente se solía mandar a un chico a la escuela para que se relacionara con otros jóvenes de su edad que podrían llegar a ser sus colegas en el futuro, y así hiciera contactos con ellos y adquiriera las maneras propias de un estudiante (Mann, 1997: 50). Pero Baoyu siempre decepciona a su familia en este sentido. Una de sus primas le dice en una ocasión:

Aunque no quieras estudiar y presentarte a los exámenes, al menos deberías alternar con los funcionarios y aprender algo acerca del mundo y la administración. Eso te ayudará el día de mañana a manejar tus propios asuntos y ganar algunos amigos. ¿Qué otro joven señor pasa el tiempo como tú, jugueteando con muchachas? (Cao y Gao, 1988a: 672- 673).

El poco interés por la carrera de funcionario es un tema recurrente en la novela que aleja al personaje de lo esperado por un hombre, sin embargo, sí que se interesa por temas considerados más superficiales como la poesía. El preceptor de Baoyu elogia la capacidad del chico para crear pareados y su originalidad para los ejercicios literarios, frente a la poca aplicación que muestra en el estudio (Cao y Gao, 1988a: 349). Junto con las otras damas acaba fundando la Academia de poesía, con lo que disfruta mucho más que con el estudio de los clásicos, ante lo que siempre ha manifestado desinterés y holgazanería. Su padre, Jia Zheng, quien vive con frustración el carácter afeminado de su hijo, se presenta como el portavoz de la decepción de que Baoyu no se esfuerce por continuar con la saga de funcionarios familiar:

En mi opinión sólo sirves para andar holgazaneando por ahí. Manchas mi suelo cuando lo pisas y mi puerta cuando te apoyas en ella (Cao y Gao, 1988a: 216).

Conocedor de los verdaderos intereses de su hijo, Jia Zheng reprende a uno de los sirvientes que le acompaña a la escuela por ser partícipes del descuido de sus estudios:

Transmite mis saludos al director de la escuela y dile de mi parte que obras como el Libro de los cantos y los Ensayos clásicos no son más que una pérdida de tiempo. Mejor sería que obligara a sus alumnos a recitar de memoria los Cuatro Libros (Cao y Gao, 1988a: 217). 
El pensamiento de Jia Zheng, que se refleja a lo largo de la novela, nos recuerda que Baoyu está sobrepasando e ignorando los límites establecidos por la convención en el ámbito de su educación y las expectativas existentes en cuanto a ser un digno heredero. Asimismo, el protagonista masculino se presenta físicamente con una forma un tanto andrógina. La primera descripción física que se hace de él, cuando Daiyu llega la mansión de los Jia, atiende a una imagen ambigua:

De tan claro, su rostro parecía empolvado; y sus labios, como pintados con carmín. Tenía una mirada llena de afecto, una conversación salpicada de sonrisas. Pero donde más se manifestaba su encanto natural era en las cejas, pues sus ojos emitían un mundo de sentimientos. Sin embargo, a pesar de lo atractivo de su apariencia, era difícil percibir qué yacía bajo ella (Cao y Gao, 1988a: 95).

En otro pasaje, el personaje incluso es confundido con una de las damas (Cao y Gao, 1988b: 215). El narrador hace hincapié en la ambigüedad del personaje más allá de lo que se muestra a la vista. La Anciana Dama también reflexionará sobre la extraña naturaleza de su nieto, ya que no sólo muestra interés por las jóvenes damas por ser hombre, como piensa su padre, sino que tiende a comportarse como ellas:

Siempre lo encuentro jugueteando con ellas. Al principio pensé que esa intimidad era la señal de que ya había crecido lo suficiente como para conocer las relaciones entre hombres y mujeres; pero al observarlo mejor comprendí que no era ésa la razón, lo cual lo hace todavía más extraño. ¿Será que en realidad debió nacer mujer? (Cao y Gao, 1988b: 907).

Tengamos aquí en cuenta las palabras de Rosalind Coward cuando dice que "parte de ser mujer es ser apreciado estéticamente" (en Edwards, 1900a: 77). Por ello, a través de la apreciación estética de Baoyu le encontramos convertido en un objeto de deseo, una posición pasiva que normalmente se asocia con la mujer y no con el hombre. Hasta la descripción de su ropa se vincula con la de una mujer, pues cuando se habla del resto de los hombres no se detalla ni su vestimenta ni su físico delicado. Baoyu también establece relaciones especiales con hombres afeminados como él, como Liu Xianglian, el príncipe de Beijing y Qin Zhong. Siempre se define a estos chicos como especialmente "apuestos", y sus descripciones, tan detalladas y delicadas siguen igualmente un patrón femenino. 
Edwards recalca que para los seguidores del taoísmo los límites entre el sexo-género eran muy flexibles. Por ejemplo, se usaban imágenes andróginas, en las que un hombre aparece muy feminizado para mostrar rechazo del mundo polvoriento y de la pasión mundana. Sin embargo, la moral confuciana es muy clara en cuanto a los límites, creando una jerarquía basada en los roles sociales que no pasa desapercibida en la novela. Por ejemplo, el hecho de que Baoyu rompa con la estricta separación de sexos que existía en el momento, no es un hecho al que no se le dé ninguna importancia, pues en boca de una de sus sirvientas encontramos estas palabras dirigidas a la madre del muchacho:

En mi humilde opinión tanto él como las jóvenes damas han dejado de ser niños, y lo que es más: la señorita Lin y la señorita Bao no son miembros de la familia, y los primos de distinto sexo deberían vivir separados. No es conveniente para ellos pasar todo el día juntos, y lo único que acarrea son preocupaciones. Además no está bien visto por la gente de fuera (Cao y Gao, 1988a: 707).

Por lo que el hecho de que Baoyu viva en el jardín junto con las demás damas solteras es determinante para identificar su naturaleza ambigua, ya que, según las normas establecidas, estaba prohibido para los hombres convivir con ellas. El Jardín de la Vista Sublime se presenta como un espacio física y conceptualmente separado en ciertos aspectos y normas del resto de la mansión, representa el "reino de las solteras" del que él forma parte. Además, según recuerda Angelina Yee, incluso su habitación está decorada como la de una mujer (1990: 633).

Otro de los puntos a tener en cuenta en este análisis no es lo que el texto dice explícitamente sino aquello que calla. Pierre Macherey nos llama la atención sobre los silencios y sus espacios: "lo que la obra no dice, lo manifiesta. Lo descubre en todas sus letras [...]. Ese silencio le da también su existencia" (1974: 85). Para este autor, es en el "inconsciente del texto" donde reside su ideología construida en torno a lo que no se habla (133). A menudo se ha denunciado desde la crítica literaria la falta de realidad de los personajes literarios al obviar aspectos insoslayables de la vida real, como en este caso sucede con el silencio existente sobre el vendaje de los pies de la mujer, cuando era una práctica completamente extendida en el siglo XVIII para las mujeres Han, hasta el punto de que en las anotaciones de un historiador de la época solo se consideraban dignas de mención las mujeres de las etnias que 
no lo realizaban (Ko, 2005: 131). Sin embargo, nunca se menciona en el texto, y es que antes del siglo XIX se tenía como un tabú en los escritos de cierto prestigio, en gran parte por sus connotaciones eróticas. Al respecto nos señala Dorothy Ko que en muchos textos de la dinastía Ming y Qing se dejaba al lector fantasear con aquello que no podía ser dicho (2005: 110). Ese reclamo de realidad nos hace ser conscientes de las cosas que el texto no dice pero insinúa y que nos revela la naturaleza del personaje de Baoyu, como sucede con sus relaciones sexuales con otros hombres.

La sexualidad de Baoyu también resulta ambigua. Pierde la virginidad con Qin Keqing en sueños y después mantiene relaciones con Xiren, su principal doncella, pero eso no evita que también se relacione sexualmente con otros hombres. El primer joven del que Baoyu se queda prendado es de Qin Zhong, de quien se dice que se "sonrojaba como una niña antes de hablar". Baoyu y él son compañeros de la escuela, en la que enseguida se extienden todo tipo de rumores sobre su relación. Se insinúan relaciones sexuales entre ellos: después de que Baoyu descubra a Qin Zhong con una joven le dice que ahora tendrá que hacer lo que él le pida, y así se resuelve la escena:

En relación con las cuentas que sin duda arregló con Qin Zhong, digamos que lo que el ojo no ve sólo puede ser sospechado, y lejos de nuestra intención seguir especulando acerca de un expediente como éste (Cao y Gao, 1988a: 320).

También es especial el trato que Baoyu les da a las mujeres. A pesar de que forman parte de su deseo, nunca las trata como objetos sino como seres dignos de admiración, superiores al hombre. Aunque debemos especificar que su respeto y admiración es hacia las jóvenes solteras, mientras que para él la mujer casada ha perdido su pureza. Aspecto que también tiene que ver con que son las mujeres casadas de la anterior generación, las responsables de la división familiar, al prometer a sus jóvenes primas y compañeras con hombres y forzarlas a abandonar el jardín, y por tanto contaminan y destruyen su mundo sentimental y femenino.

No será hasta el final de la novela cuando Baoyu parezca alejarse del lado femenino que le define y cumpla con las expectativas paternas, incluso podríamos decir, expectativas confucianas. El protagonista hasta ese momento dedicó la mayor parte de su vida a estar con las chicas y 
a dejarse llevar por sus deseos, al contrario de lo esperado de un chico de una familia de élite en el siglo XVIII, que no era buscar la realización personal sino prosperar para brindar un buen porvenir a sus descendientes y honor a sus ancestros, lo que suponía ganar un puesto oficial en el funcionariado de la china imperial, y cumplir con lo establecido por la piedad filial.

\subsection{Xifeng, una mujer dentro de un mundo de hombres}

En la narración, el papel de Baoyu y el de Xifeng parecen haberse invertido, inclinándose el carácter de él hacia lo poético y sentimental y el de ella, hacia lo práctico. El destino de estos dos personajes está unido, aunque observamos una diferencia fundamental en la manera en la que desdibujan los límites entre lo femenino y lo masculino. Mientras que con Baoyu nos enfrentábamos tanto a una transgresión interior de su personalidad como en la descripción física, con la de Xifeng, nos referimos meramente a una cuestión de actitud, ya que su belleza siempre es descrita dentro de los cánones tradicionales. La primera referencia que hay de Xifeng en el texto ya es reveladora:

Desde que se casó [Jia Lian] se ha visto desplazado por su esposa, una mujer a la que todos elogian. Dicen que es muy guapa y elocuente, y tan astuta y llena de recursos que no hay hombre a su alrededor que se le pueda comparar (Cao y Gao, 1998a: 73).

Las comparaciones de Xifeng con los hombres son abundantes a lo largo de la narración. En una ocasión Qin Keqing le dice que "ni los hombres de correaje y gorra oficial se le pueden comparar" (Cao y Gao, 1988a: 275). Sorprendentemente este personaje ocupa el papel de nuera en la familia, el que, según Amelia Sáiz "es el que goza de menor prestigio y, en general, el que conlleva mayor sufrimiento" dentro de la jerarquía confuciana tradicional (2001: 28). La nuera es una persona que viene de fuera de la familia, una extraña que entra a formar parte de ella por un acuerdo matrimonial. Sin embargo, la posición de Xifeng es privilegiada; de las cuatro familias nobles que aparecen en la novela está emparentada con tres: nacida Wang, casada con un Jia, y con su tía paterna casada con un Xue. También es la favorita de la Anciana Dama, que es Shi. Aprovechándose de ello, conseguirá dar rienda suelta a sus deseos de poder, que de otra manera quizá hubieran estado reprimidos. 
Para una mujer casada, encargarse de la administración doméstica era algo común, pero no se le otorgaba demasiado poder, pues se consideraba la peor sustancia que podía corromper a una mujer. El matrimonio suponía el acceso de la mujer al poder del marido o la oportunidad de ejercerlo a través de sus hijos. Wang Xifeng se presenta a la vez como el personaje femenino más corrupto y el que concentra más poder. Las otras mujeres casadas se describen como sujetos con poca iniciativa y siempre a la sombra de sus maridos. Incluso la Dama Xing es insultada por la Anciana Dama por llevar demasiado lejos las Tres Obediencias y siendo una esclava de los deseos de su marido. Por el contrario, Xifeng siempre busca la manera de imponer su voluntad, incumpliendo este precepto. Cuando su marido, Jia Lian, se casa en secreto con la segunda hermana You, dice de ella:

En lo tocante a suavidad y obediencia, la segunda hermana era diez veces mejor que Xifeng, ya que todo se lo consultaba a su marido y nunca se atrevía a tomar una decisión por cuenta propia o a confiar exclusivamente en su propio juicio (Cao y Gao, 1988b: 606).

Xifeng cada vez adquiere más poder y con su poder más independencia, hasta el punto de tomar decisiones por su marido y manejar los asuntos de la casa por cuenta propia sin consultar a los demás. Cuando Xifeng es advertida en sueños por Qin Keqing que la mansión está entrando en la ruina y que les esperan años duros, comenzará a manejar la economía intentando falsear las cuentas y haciendo negocios para ganar dinero a escondidas. Angelina Yee identifica precisamente la masculinidad de Xifeng en su ambición, codicia e hipocresía (1990: 641).

La inversión de los papeles también se manifiesta en el poco interés que muestra Baoyu por el poder, cuando su posición es la de heredero principal, así como la sed de poder de Xifeng, cuando solo es la mujer de uno de los descendientes de la familia:

Para Xifeng no había nada tan gratificante como poder exhibir su capacidad administrativa. Aunque manejaba la mansión Rong con gran competencia, nunca se le habían confiado grandes acontecimientos, bodas o funerales, y temía que los demás no estuvieran plenamente persuadidos de su eficiencia; por eso anhelaba una oportunidad (Cao y Gao, 1988a: 285-286). 
Además a Xifeng se la retrata siempre como una mujer celosa (la fidelidad solo se exigía a las mujeres), que entra en cólera cada vez que se entera de los escarceos amorosos de su marido. Entre sus maquinaciones podemos destacar que consiguiera que una de las concubinas de su marido se suicide. Pero habría que tener en cuenta que los celos de Xifeng, se relacionan estrechamente con sus deseos de poder, pues ella no había sido capaz de ofrecer un descendiente varón a la familia, y si otra mujer lo hiciera haría tambalear su posición.

\section{La transgresión del género: la glorificación frente a la caída}

Los acontecimientos que les suceden a Baoyu y Xifeng están expuestos en paralelo a lo largo de la novela, incluso a veces en el mismo episodio y a veces en el mismo tiempo. Y en paralelo podemos también analizar su destino y qué solución ofrece la novela en cuanto a la transgresión de género que comenten estos dos personajes.

Desde el capítulo setenta y dos se dice que Xifeng está perdiendo sangre menstrual, lo que le provoca bastante fatiga, sin embargo, ella no quiere renunciar al manejo de los asuntos de la casa. La pérdida de sangre se halla en paralelo con la pérdida de poder, y por tanto con el castigo de haber transgredido los límites del papel de la mujer. El esfuerzo de Xifeng por mantener su mundo resulta en el aborto de un feto femenino, haciéndole pagar el precio por haber cruzado los límites establecidos para una mujer.

Uno de los pasajes donde mejor se refleja el fin de Xifeng es en el funeral de la Anciana Dama, cuando las arcas familiares están devastadas y la familia está pasando por su peor momento. La mujer agotada hasta la extenuación, reprime su rabia hasta que las lágrimas le encharcan los ojos:

Todo se le volvió oscuro y sintió un sabor dulce. Entonces la boca se le llenó de sangre, las rodillas le cedieron y se desmoronó. Ping'er corrió a sostenerla, y ella siguió vomitando chorros de sangre (Cao y Gao, 2005: 634).

Se pone en manos de la protagonista parte de la responsabilidad de la decadencia familiar y su muerte representa el castigo de sus excesos, mientras que la solución de los problemas se enfoca en Baoyu. 
El debate interior de Baoyu entre las dos esferas, que también se puede observar en la relación que mantiene con dos de las mujeres protagonistas Daiyu y Baochai (la primera invoca sus valores femeninos, la segunda resalta los masculinos), se resolverá con la inclinación de la balanza hacia los valores tradicionales masculinos. El protagonista será engañado para casarse con Baochai, mientras Daiyu muere de amor despreciada por la familia por su debilidad de carácter y falta de corrección. Un desenlace que no deja de ser una elección forzada por la sociedad, pues él pensaba que se desposaba con Daiyu.

A pesar de su reticencia inicial por Baochai, poco a poco asumirá la situación guiado por la rectitud de su mujer. Baoyu cumplirá con todos sus deberes como hombre, obtiene un buen puesto en el examen imperial y deja a Baochai embarazada, dejando un descendiente que continúe con la saga familiar y cumpliendo así con los preceptos de la piedad filial. Después abandonará el polvoriento mundo acompañado de dos monjes, una taoísta y uno budista, que transitan entre el mundo de la realidad y la ilusión a lo largo de la novela. Mientras Xifeng deja el mundo tras una larga agonía y es castigada por su transgresión, Baoyu no solo logra partir como un héroe cumpliendo a tiempo sus designios como hombre, sino que también es liberado del mundo real y de sus imposiciones.

\section{Conclusiones}

Al principio de estas páginas reflexionamos sobre cómo el género, entendido como constructo social, imponía una serie de normas sobre los personajes femeninos que limitaba muchos aspectos de su vida, desde las relaciones que se podían tener hasta los libros que se debían leer o las actividades a las que se podían dedicar. Los dos personajes transgresores, Baoyu y Xifeng, nos cuestionan en un primero momento la rigidez de esas categorías, sin embargo, en nuestra opinión, el desenlace de la novela las viene a reforzar. Al personaje masculino se le permite abandonar el mundo real ${ }^{20}$, pero no sin antes cumplir con los deberes impuestos por la moral de su época; sin embargo, al personaje femenino se le hace morir cruelmente, por lo que nos inclinamos a pensar que en el fondo ninguna transgresión está amparada por la ideología de la

\footnotetext{
${ }^{20}$ No olvidemos que desde el comienzo se le relaciona con un origen casi mítico lo que facilita la lógica narrativa.
} 
novela. Y en el caso de presentar cierta permisividad, solo se manifiesta con el caso de Baoyu, es decir, con el hombre. Cabría preguntarse entonces si las normas de corrección y propiedad, aquí representadas por los límites establecidos por la categoría de género, también se imponían sobre el proceso creativo en la elaboración de una obra de ficción que debía ser aceptada por el lector y la moral de su tiempo.

\section{Bibliografía}

Beauvoir, Simone de. 1970. El segundo sexo (Tomo I Los hechos y los mitos. Tomos II La experiencia vivida). Buenos Aires: Ediciones Siglo XX.

Butler, Judith. 2007. Gender Trouble (Feminism and subversion of Identity). Nueva York: Routledge.

Cao, Xueqin \& Gao, E. 1988a. Sueño en el Pabellón Rojo. Memorias de una Roca, Tomo I. Granada: Universidad de Granada. Traducción de Tu Xi, revisada, corregida y anotada por Zhao Zhenjiang y José Antonio García Sánchez.

Cao, Xueqin \& Gao, E. 1988b. Sueño en el Pabellón Rojo. Memorias de una Roca, Tomo II. Granada: Universidad de Granada. Traducción de Tu $\mathrm{Xi}$, revisada, corregida y anotada por Zhao Zhenjiang y José Antonio García Sánchez.

Cao, Xueqin \& Gao, E. 2005. Sueño en el Pabellón Rojo. Memorias de una Roca, Tomo III. Granada: Universidad de Granada. Traducción de Zhao Zhenjiang, revisada por Alicia Relinque Eleta y José Antonio García Sánchez.

Cheng, Anne. 2003. Historia del pensamiento chino. Barcelona: Bellaterra.

Cixous, Helene. 1995. La risa de la medusa. Barcelona: Anthropos.

Confucio. 1997. Lunyu. Reflexiones y enseñanzas. Barcelona: Editorial Kairós. Traducción y prólogo a cargo de Anne-Hélène Suárez Girard.

Edwards, Louise. 1990a. Gender Imperatives in Hongloumeng: Baoyu's Bisexuality. Chinese Literature: Essays, Articles, Reviews (CLEAR) 12: 69-81.

Edwards, Louise. 1990b. Women in Hongloumeng: Prescriptions of Purity in the Femininity of Qing Dynasty China. Modern China 16(4): 407-429.

Epstein, Maram. 2007. Bound by Convention: Women's Writing and the Femenine Voice in Eighteenth Century China. Tulsa Studies in Women's Literature 26(1): 97-105.

Gajeri, Elena. 2002. Los estudios sobre mujeres y los estudios de género. En Gnisci, Armando (ed.) Introducción a la literatura comparada. Barcelona: Editorial Crítica. 
Ge, Liangyan. 2002. The Mythic Stone in Honglou meng and an Intertext of Ming-Qing Fiction Criticism. The Journal of Asian Studies 61(1): 57-82. Ko, Dorothy. 2005. Cinderella's Sisters. A Revisionist History of Footbinding. California: University of California Press.

Lai, Karyn. 2000. The Daodejing: resources for contemporary feminist thinking. Journal of Chinese Philosophy 27(2): 131-153.

Lijing. Tratado de los Ritos. Vol I Libros I- VIII. Traducción de Fulvio Scarcia y Leonardo La Rosa y coordinada por Julio López Saco.

Li, Wai-Yee. 1999. Heroic Transformations: Women and National Trauma in Early Qing Literature. Harvard Journal of Asiatic Studies 59(2): $363-$ 443.

Macherey, Pierre. 1974. Para una teoría de la producción literaria. Ediciones de la biblioteca de la Universidad Central de Venezuela.

Mann, Susan. 1997. Precious Records. Women en China's Long Eighteenth Century. Stanford: Stanford University Press.

Moi, Toril. 2006. Teoría literaria feminista. Madrid: Cátedra.

Plaks, Andrew H. 1976. Archetype and Allegory in the Dream of the Red Chamber. New Jersey: Princeton University Press.

Raphals, Lisa. 1998. Sharing the Light. Representations of Women and Virtue in Early China. Albany: State University of New York Press.

Sáiz López, Amelia. 2001. Utopía y género. Las mujeres chinas en el siglo XX. Barcelona: Bellaterra.

Waltner, Ann. 1981. Widows and Remarriage in Ming and Early Qing China. En Guisso \& Johannesen (ed.) Women in China. Youngstown, NY: Philo Press.

Waltner, Ann. 1998. On not becoming a Heroine: Lin Daiyu and Cui Ying-ying. Signs 15(1): 61-78.

Wawrytko, Sandra A. 2001. Kongzi as feminist: Confucian self-cultivation in a contemporary context. Journal of Chinese Philosophy 27(2): 171-186.

Wu, Hung. 1997. Beyond Stereotypes: The Twelve Beauties in Qing Court Art and the Dream of the Red Chamber. En Widmer, Ellen (ed.) Writing Women in Late Imperial China. Stanford: Stanford University Press.

Yang, Michael. 1996. Naming in Honglou meng. Chinese Literature: Essays, Articles, Reviews (CLEAR) 18: 69-100.

Yee, Angelina C. 1990. Counterpoise in Honglou meng. Harvard Journal of Asiatic Studies 50(2): 613-650.

Yu, Anthony C. 1997. Rereading the Stone: Desire and the Making of Fiction in Dream of the Red Chamber. New Jersey: Princeton University Press.

Zhao, Rong. 1982. 婚姻自由的呐喊男女平等的讴歌 Hunyin ziyou de nahan nannüpingdeng de ouge (Un grito por la libertad en el matrimonio y un elogio a la igualdad de sexos). 《贵阳师院学报》guiyan shiyuan xuebao. Vol. 1: 55-65. 